\title{
Tonic clonic status epilepticus
}

\author{
Simon Shorvon
}

Tonic clonic status epilepticus can be defined as a condition in which prolonged or recurrent tonic clonic seizures persist for $30 \mathrm{~min}$ utes or more. From indirect studies, the annual incidence of tonic clonic status has been estimated to be approximately 18-28 cases per 100000 persons (9-14000 new cases each year in the UK, or 45-70 000 cases in the USA). ${ }^{12}$ It is most frequent in children, the mentally handicapped, and in those with structural cerebral pathology (especially in the frontal areas). In established epilepsy, status may be precipitated by drug withdrawal, intercurrent illness or metabolic disturbance, or the progression of the underlying disease, and is more common in symptomatic than in idiopathic epilepsy. About 5\% of all epileptic adult clinic patients will have at least one episode of status in the course of their epilepsy, ${ }^{12}$ and in children the proportion is higher $(10-25 \%) .^{1-3}$ Most status episodes, however, do not develop in known epileptic patients, and in such cases are almost always due to acute cerebral disturbances; common causes are cerebral infection, trauma, cerebrovascular disease, cerebral tumour, acute toxic or metabolic disturbance, febrile illness (in children). Recent studies have shown status to account for about $3.5 \%$ of admissions to neurological intensive care, ${ }^{4}$ and $0 \cdot 13 \%$ of all visits to a university hospital casualty department. ${ }^{5}$ The mortality of tonic clonic status is about 5-10\%, most patients dying of the underlying condition, rather than the status itself or its treatment. ${ }^{12}$ Permanent neurological and mental deterioration may result from status, particularly in young children, the risks of morbidity being greatly increased the longer the duration of the status episode. ${ }^{36}$ Tonic clonic status is only one of the forms of status epilepticus (see table 1), and indeed is not the most common. Nevertheless, unlike other types, it is a medical emergency. Treatment is urgent because the longer seizures continue, the worse the outcome and the more hazardous is therapy. Successful management is a balance between the conflicting requirements of controlling seizure activity as quickly as possible, and minimising physiological changes and medical complications.

\section{Pathophysiology of tonic clonic status epilepticus}

The pattern of seizures in tonic clonic status evolves over time. There is often a premonitory stage of minutes or hours, during which epileptic activity increases in frequency or severity from its habitual level. This clinical deterioration is an augury, often stereotypic, of impending status, and urgent therapy may well prevent its full development. At the onset of status, the attacks typically take the form of discrete grand mal seizures. As time passes, however, the convulsive motor activity often evolves, first to become continuous, and then clonic jerking becomes less pronounced and less severe, and finally ceases altogether. This is the stage of "subtle status epilepticus", ${ }^{78}$ by which time, the patient will be deeply unconsciousness, and the prognosis is poor. In parallel to this clinical evolution, there is also sometimes a progressive change in the EEG, ${ }^{9}$ although how consistently such a progressive clinical and EEG pattern occurs is not known. Autonomic changes in status can be profound, and dominate the clinical picture, These include hyperpyrexia, tachycardia, cardiac arrhythmia, blood pressure changes, apnoea, sweating, hypersecretion and massive noradrenalin and adrenalin release. Other profound endocrine changes also occur.

The physiological changes in status are often divided into two phases, the transition from phase 1 to 2 occurring after about 30-60 minutes of continuous seizures. ${ }^{20-12}$ Whilst this is a generally useful concept, it must be

Table 1 Classification of status epilepticus (derived from Shorvon ${ }^{2}$ )

STATUS EPILEPTICUS CONFINED TO THE NEONATAL PERIOD

Neonatal status

Status in neonatal epilepsy syndromes

STATUS EPILEPTICUS CONFINED TO INFANCY AND CHILDHOOD

Infantile spasm (West syndrome)

Febrile status epilepticus

Status in childhood myoclonic syndromes

Status in benign childhood partial epilepsy syndromes

Electrical status during slow wave sleep (ESES)

Syndrome of acquired epileptic aphasia

STATUS EPILEPTICUS OCCURRING IN

CHILDHOOD AND ADULT LIFE

Tonic clonic status

Absence status

Epilepsia partialis continua (EPC)

Myoclonic status in coma

Specific forms of status in mental retardation

Myoclonic status in other epilepsy syndromes

Nonconvulsive simple partial nonconvulsive status

Complex partial status

Boundary syndromes

STATUS EPILEPTICUS CONFINED TO ADULT LIFE De Novo absence status of late onset 
recognised that there is great variation. Both the rate and extent of physiological change are dependent on many other factors, including the anatomical site of the epileptic focus, the severity of the seizures, the underlying aetiology and the treatment employed. Nevertheless, this staging of changes is helpful in devising a rational plan for therapy.

Phase 1

From the onset of status, seizure activity greatly increases cerebral metabolism. Physiological mechanisms are initially sufficient largely to compensate for this pertubation. Cerebral blood flow is greatly increased, and initially the delivery of glucose to the active cerebral tissue is maintained. Later systemic and cerebral lactate levels rise, and a profound lactic acidosis may develop. ${ }^{13}$ There are massive cardiovascular and autonomic changes. Blood pressure rises, as does cardiac output and rate. The autonomic changes result in sweating, hyperpyrexia, bronchial secretion, salivation and vomiting, and adrenalin and noradrenalin release. Endocrine and autonomic changes also cause an early rise in sugar levels.

\section{Phase 2}

As the seizure activity progresses, the compensatory physiological mechanisms begin to fail. Cerebral autoregulation breaks down progressively, and thus cerebral blood flow becomes increasingly dependent on systemic blood pressure. ${ }^{10-12}$ Hypotension develops due to seizure-related autonomic and cardiorespiratory changes and drug treatment, and in terminal stages may be severe. The falling blood pressure results in falling cerebral blood flow and cerebral metabolism. The high metabolic demands of the epileptic cerebral tissue cannot be met and ischaemic or metabolic damage may ensue. ${ }^{14-16}$ The tendency to hypotension can be greatly exacerbated by intravenous antiepileptic drug therapy, especially if infusion rates are too fast. Pressor agents are often necessary in prolonged therapy.

Systemic and cerebral hypoxia are common in status, due to: central respiratory failure (greatly exacerbated by drug medication); the increased oxygen requirements of convulsions; and later pulmonary artery hypertension and pulmonary oedema. ${ }^{211}$ Because of this, assisted ventilation is often required early in the course of status.

Intracranial pressure may rise precipitously in status. The combined effects of systemic hypotension and intracranial hypertension can result in a compromised cerebral circulation and cerebral oedema, particularly in children. ${ }^{12}$ Intracranial pressure monitoring is advisable in prolonged severe status, especially in children, when raised intracranial pressure is suspected; the need for active medical or surgical therapy is, however, largely determined by underlying pathology.

Cardiovascular changes in late status can also be serious. Pulmonary hypertension and oedema are frequent, even in the presence of systemic hypotension. Pulmonary artery pressures can rise to dangerous levels, well in excess of the osmotic pressure of blood, causing oedema and stretch injuries to lung capillaries. ${ }^{17}$ Cardiac arrhythmias in status are the result of direct seizure-related autonomic activation, catecholamine release, hypoglycaemia, lactic acidosis, electrolyte disturbance, or cardiotoxic therapy. The autonomic effects are sometimes caused by simultaneous discharges in sympathetic and parasympathetic pathways. Intravenous sedatives depress cardiac function, and the drug effects can be potentiated by pre-existing compromise of cardiac function. Inspite of the greatly increased demand, cardiac output can fall due to decreasing left ventricular contractility and stroke volume, ${ }^{18}$ causing cardiac failure. The prodigious noradrenalin and adrenalin release also contribute to the cardiac dysfunction, arrhythmia and tachycardia. Measures to control cardiac failure and arrythmia are often needed.

Spectacular hyperpyrexia can also develop in status, ${ }^{713}$ and may also require specific treatment.

There are many metabolic and endocrine disturbances in status, the commonest and most important are: acidosis (including lactic acidosis), hypoglycaemia, hypo/hyperkalaemia, and hyponatraemia. Lactic acidosis is almost invariable in major status epilepticus, ${ }^{13}$ from its onset, due to neuronal and muscle activity, the acceleration of glycolysis, tissue hypoxia, impaired respiration, and catecholamine release. Acute tubular necrosis due to myoglobinuria or dehydration, and occasionally fulminant renal failure may occur. Hepatic failure is a not uncommon terminal event in status, due to other physiological disturbances, drug treatment or underlying disease. Rhabdomyolysis, resulting from persistent convulsive movements, can develop early in status and precipitate renal failure if severe, and can be prevented by artificial ventilation and paralysing drugs. Disseminated intravascular coagulation is another rare but serious development in status which will require urgent therapy. Other medical complications in status are listed in table 2 , and are usually due to the autonomic activity, seizures or drug treatment.

\section{Antiepileptic drug pharmacology}

As fast drug absorption is essential in status, all drugs are administered parenterally. Midazolam and paraldehyde can be given intramuscularly, diazepam midazolam and paraldehyde by the rectal route, but all others must be given by intravenous injection. It is desirable in status for drugs to have a rapidonset and a prolonged duration of action. Unfortunately, rapidly-acting drugs are usually highly lipid soluble (for example, diazepam, midazolam, chlormethiazole, propofol), tending to redistribute quickly from cerebral tissue to accumulate in the larger peripheral lipid compartments (fat stores). Because of this, after a single intravenous 
Table 2: Medical complications in tonic clonic status epilepticus (derived from Shorvon ${ }^{2}$ )

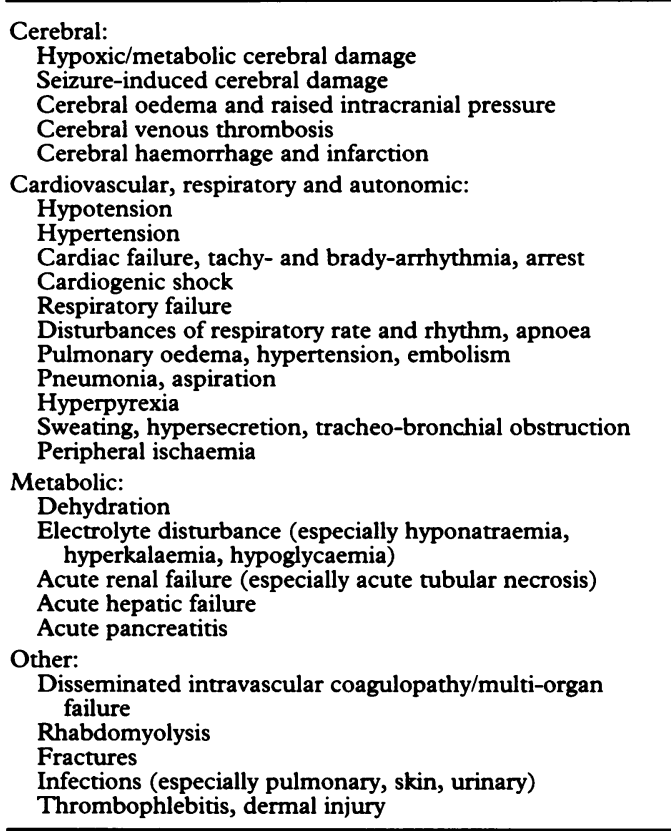

injection, there is a rapid fall in cerebral drug levels; the initial injection has therefore a short-lived effect. Repeated dosing of such lipid-soluble drugs results in progressive drug accumulation in the fat stores. The clinical effect of subsequent doses will therefore differ greatly from that of the first injection, as redistribution to the already drug-rich fat stores will not readily occur. In this situation, new drug administration can cause very high cerebral levels which persist for long periods of time. These high levels may precipitate hypotension, sedation or cardiorespiratory failure; a serious risk with the repeated administration of diazepam, midazolam, chlormethiazole, clonazepam, pentobarbitone, or thiopentone. Less lipid soluble drugs are relatively slower to act, but have a much longer-lasting effect without a high risk of accumulation (for example, phenytoin, lorazepam, phenobarbitone). For lipid-soluble drugs, the rate of injection must also be carefully monitored, as too rapid a rate of administration will cause very high cerebral levels, and the risk of sudden cardio-respiratory arrest or hypotension. For less lipid soluble drugs (such as, lorazepam), the rate of injection is not critical. An ideal antiepileptic drug: should have no active metabolites (diazepam, midazolam, lignocaine and thiopentone have active metabolites); should not interact with other medication; should not have saturable metabolism (both phenytoin and thiopentone have saturable pharmacokinetics at therapeutic levels); should not be unduly affected by hepatic or renal blood flow or disease (chlormethiazole is an example of a drug whose metabolism is greatly effected by both hepatic disease and changes in hepatic blood flow); should show no tendency to autoinduction (thiopentone, phenobarbitone and phenytoin are all subject to strong autoinduction); should have strong antiepileptic action (the non-barbiturate anaesthetics have little or no intrinsic antiepileptic action, a conundrum for their use in status which has not been fully explored); should be stable in solution and unreactive with giving sets (a problem with paraldehyde, diazepam, thiopentone).

\section{General measures}

For the new patient presenting as an emergency in status, it is helpful to plan therapy in a series of progressive phases (table 3 ).

First stage (0-10 minutes):

1) Oxygen and cardio-respiratory resuscitation: It is first essential to assess cardio-respiratory function, to secure the airway and resuscitate where necessary. Oxygen should always to administered, as hypoxia is often unexpectedly severe.

Second stage (1-60 minutes):

1) Monitoring: Regular neurological observations, measurements of pulse, blood pressure, ECG and temperature should be initiated. Metabolic abnormalities may cause status, or develop during its course, and biochemical, blood gasses, $\mathrm{pH}$, clotting and haematological measures should be monitored.

2) Emergency anticonvulsant therapy: should be started (see below)

3) Intraveous lines should be set up for fluid replacement and drug administration (preferably with $0.9 \%$ sodium chloride (normal saline) rather than $5 \%$ glucose solutions). Drugs should not be mixed, and if two antiepileptic drugs are needed (for example, phenytoin and diazepam), two intravenous lines should be sited. The lines should be in large veins, as many antiepileptic drugs cause phlebitis and thrombosis at the site of infusion. Arterial lines must never be used for drug administration.

4) Emergency investigations: Blood should

Table 3 General measures (derived from Shorvon ${ }^{2}$ )

\begin{tabular}{l}
\hline (0-10 minutes): \\
Assess cardiorespiratory function \\
Secure airway and resuscitate \\
Administer oxygen \\
2 (0-60 minutes): \\
Institute regular monitoring (see text) \\
Emergency antiepileptic drug therapy (see text) \\
Set up intravenous lines \\
Emergency investigations (see text) \\
Administer glucose (50 ml of $50 \%$ solution) and/or \\
intravenous thiamine ( 250 mg) as HPIV parenterovite) \\
where appropriate \\
Treat acidosis if severe \\
3 (0-60/90 minutes) \\
Establish aetiology \\
Identify and treat medical complications \\
Pressor therapy where appropriate \\
4 (30-90 minutes) \\
Transfer to intensive care \\
Establish intensive care and EEG monitoring (see text) \\
Initiate seizure and EEG monitoring \\
Initiate intracranial pressure monitoring where appropriate \\
Initiate long-term maintenance antiepileptic therapy \\
These 4 stages should be followed chronologically; the first \\
and second withi 10 minutes, and stage 4 (transfer to ITU) in \\
most settings within $60 / 90$ minutes of presentation.
\end{tabular}


be drawn for the emergency measurement of blood gases, sugar, renal and liver function, calcium and magnesium levels, full haematological screen (including platelets), blood clotting measures, and anticonvulsant levels. $50 \mathrm{ml}$ of serum should also be saved for future analysis especially if the cause of the status is uncertain. Other investigations depend on the clinical circumstances.

5) Intravenous glucose and thiamine: Fifty $\mathrm{ml}$ of a $50 \%$ glucose solution should be given immediately by intravenous injection if hypoglycaemia is suspected. If there is a history of alcoholism, or other compromised nutritional states, $250 \mathrm{mg}$ of thiamine (for example, as the high potency intravenous formulation of Parenterovite, $10 \mathrm{ml}$ of which contains $250 \mathrm{mg}$ ) should also be given intravenously. This is particularly important if glucose has been administered, as a glucose infusion increases the risk of Wernicke's encephalopathy in susceptible patients. Intravenous high dosage thiamine should be given slowly (for example, $10 \mathrm{ml}$ of high potency Parenterovite (over 10 minutes), with facilities for treating the anaphylaxis which is a potentially serious side effect of parenterovite infusions. Routine glucose administration in non-hypoglycaemic patients should be avoided as there is some evidence that this can aggravate neuronal damage.

6) Acidosis: If acidosis is severe, the administration of bicarbonate has been advocated in the hope of preventing shock, and mitigating the effects of hypotension and low cerebral blood flow. In most cases, however, this is unnecessary and more effective is the rapid control of respiration and abolition of motor seizure activity.

\section{Third stage (1-60/90 minutes)}

1) Establish aetiology: The ranges of causes of status depend primarily on age, the presence or absence of established epilepsy, and the investigations required depend on clinical circumstances. CT scanning and CSF examination are often necessary, the latter should be carried out only with facilities for resuscitation available as intracranial pressure is often elevated in status.

If the status has been precipitated by drug withdrawal, the immediate restitution of the withdrawn drug, even at lower doses, will usually rapidly terminate the status.

2) Physiological changes and medical complications: The physiological changes of uncompensated status, listed above, may require specific therapy. Active treatment is most commonly required for: hypoxia, hypotension, raised intracranial pressure, pulmonary oedema and hypertension, cardiac arrythmias, cardiac failure, lactic acidosis, hyperpyrexia, hypoglycaemia, electrolyte disturbance, acute hepatic or renal failure, rhabdomyolysis, disseminated intravascular coagulation.

3) Pressor therapy: Dopamine is the most commonly used pressor agent, given by continuous intravenous infusion. The dose should be titrated to the desired haemody- namic and renal responses (usually initially between $2-5 \mu \mathrm{g} / \mathrm{kg} /$ minutes, but this can be increased to over $20 \mu \mathrm{g} / \mathrm{kg} /$ minutes in severe hypotension). Dopamine should be given into a large vein as extravasation causes tissue necrosis. ECG monitoring is required, as conduction defects may occur, and particular care is needed in dosing in the presence of cardiac failure.

\section{Fourth stage (30-90 minutes):}

1) Intensive care: If seizures are continuing inspite of the measures taken above, the patient must be transferred to an intensive care environment, and the usual intensive care measures instituted.

2) Intensive care monitoring: In severe established status, intensive monitoring may be required, including: intra-arterial blood pressure, capnography, oximetry, central venous pressure and Swan-Ganz monitoring.

3) Seizure and EEG monitoring: In prolonged status, or in comatose ventilated patients, motor activity can be barely visible. In this situation, continuous EEG monitoring using a full EEG or a cerebral function monitor is necessary. The latter must be calibrated individually, and then can register both burst suppression and seizure activity. Burst suppression provides an arbitrary physiological target for the titration of barbiturate or anaesthetic therapy. Drug dosing is commonly set at a level which will produce burst suppression with interburst intervals of between 2-30 seconds.

4) Intracranial pressure (ICP) monitoring and cerebral oedema: Continuous ICP monitoring is advisable, especially in children in the presence of persisting, severe or progressive elevated intracranial pressure. The need for active therapy is usually determined by the underlying cause rather than the status. Intermittent positive pressure ventilation, high-dose corticosteroid therapy (4 mg dexamethasone every 6 hours), or mannitol infusion may be used (the latter is usually reserved for temporary respite for patients in danger of tentorial coning). Neurosurgical decompression is occasionally required.

5) Long-term anticonvulsant therapy: Longterm maintenance anticonvulsant therapy must be given in tandem with emergency treatment. The choice of drug depends on previous therapy, the type of epilepsy and the clinical setting. If phenytoin or phenobarbitone have been used in emergency treatment, maintenance doses can be continued orally (through a nasogastric tube) guided by serum level monitoring. Other maintenance antiepileptics can be started also, giving oral loading doses.

\section{Stages in drug treatment}

The drug treatment of tonic clonic status epilepticus can also be usefully divided into stages $^{2}$ (table 4). A suggested regime for a typical new case presenting as an emergency is given in table 5 . 
Table 4 Antiepileptic drugs used in status epilepticus (derived from Shorvon ${ }^{2}$ )

\begin{tabular}{|c|c|}
\hline $\begin{array}{l}1 \text { Premonitory stage: } \\
\text { Diazepam } \\
\text { Midazolam } \\
\text { Paraldehyde }\end{array}$ & $\begin{array}{l}\text { Method of administration } \\
\text { IV bolus or rectal solution } \\
\text { IM, IV bolus, rectal solution } \\
\text { Rectal solution, IM }\end{array}$ \\
\hline $\begin{array}{l}2 \text { Early status: } \\
\text { First line: } \\
\text { Lorazepam } \\
\text { Diazepam }\end{array}$ & $\begin{array}{l}\text { IV bolus (repeated if necessary) } \\
\text { IV bolus (repeated if necessary) }\end{array}$ \\
\hline $\begin{array}{l}\text { Second line: } \\
\text { Lignocaine } \\
\text { Clonazepam } \\
\text { Paraldehyde } \\
\text { Phenytoin }\end{array}$ & $\begin{array}{l}\text { IV bolus and short infusion } \\
\text { IV bolus } \\
\text { Rectal solution, IM } \\
\text { IV bolus }\end{array}$ \\
\hline $\begin{array}{l}3 \text { Established status } \\
\text { First line: } \\
\text { Phenobarbitone } \\
\text { Phenytoin (+/- diazepam) } \\
\text { Chlormethiazole }\end{array}$ & $\begin{array}{l}\text { IV loading and then repeated IV/oral boluses } \\
\text { IV loading and then repeated IV/oral boluses } \\
\text { IV bolus and continuous infusion }\end{array}$ \\
\hline $\begin{array}{l}\text { Second line: } \\
\text { Clonazepam } \\
\text { Paraldehyde } \\
\text { Diazepam } \\
\text { Midazolam }\end{array}$ & $\begin{array}{l}\text { IV bolus or short infusion } \\
\text { IV infusion } \\
\text { Short IV infusion } \\
\text { Short IV infusion }\end{array}$ \\
\hline $\begin{array}{l}4 \text { Refractory status: } \\
\text { First line: } \\
\text { Thiopentone } \\
\text { Propofol }\end{array}$ & $\begin{array}{l}\text { IV bolus and infusion } \\
\text { IV bolus and infusion }\end{array}$ \\
\hline $\begin{array}{l}\text { Second line: } \\
\text { Pentobarbitone } \\
\text { Isoflurane } \\
\text { Etomidate }\end{array}$ & $\begin{array}{l}\text { IV bolus and infusion } \\
\text { Inhalation } \\
\text { IV bolus and infusion }\end{array}$ \\
\hline (IV = intravenous; IM = intr & ectal administration) \\
\hline
\end{tabular}

Table 5 Emergency antiepileptic drug regimen for status in newly-presenting adult patients (derived from Shorvon ${ }^{2}$ )

Premonitory stage: Diazepam 10-20 mg given IV or rectally, repeated once 15 minutes later if status continues to threaten. IV injection at a rate not exceeding $2-5 \mathrm{mg} / \mathrm{minute}$

If seizures continue, treat as below:

Early status: $\quad$ Lorazepam (IV) $0.07 \mathrm{mg} / \mathrm{kg}$ (usually a $4 \mathrm{mg}$ bolus, repeated once after 10 minutes; rate not critical)

If seizures continue 30 minutes after first injection, treat as below:

Established status: Phenobarbitone bolus of $10 \mathrm{mg} / \mathrm{kg}$ at a rate of $100 \mathrm{mg} / \mathrm{minute}$ (usually $700 \mathrm{mg}$ over 7 minutes in an adult).

Phenytoin infusion at a dose of $15-18 \mathrm{mg} / \mathrm{kg}$ at a rate of $50 \mathrm{mg} /$ minute (eg $1000 \mathrm{mg}$ in 20 minutes; with diazepam if not already givenIV $10-20 \mathrm{mg}$ );
If seizures continue for $30 / 60$ minutes or longer, treat as below:

Refractory status: General anaesthesia, with either propofol or thiopentone. Anaesthetic continued for 12-24 hours after the last clinical or electrographic seizure, then dose tapered.

In the above scheme, the refractory stage (general anaesthesia) is reached $60 / 90$ minutes after the initial therapy. This scheme is suitable for usual clinical hospital settings. In some

situations, general anaesthesia should be initiated earlier, and occasionally, should be delayed.

Premonitory stage

In patients with established epilepsy, tonic clonic status seldom develops without warning. Usually, a prodromal phase (the premonitory stage) presages status, during which seizures become increasingly frequent or severe. Urgent drug treatment will usually prevent the evolution into true status. One of three drugs is used (diazepam, midazolam or paraldehyde), and each is highly effective.

The earlier treatment is given the better. It is easier to prevent the evolution of epilepsy to status epilepticus than to treat the established condition. If the patient is at home, antiepileptic drugs should be administered before transfer to hospital, or in the casualty department before transfer to the ward. The acute administration of either diazepam and midazolam will cause drowsiness or sleep, and occasionally cardiorespiratory collapse, and should be carefully supervised.
Stage of early status epilepticus (0-30 minutes):

Once status epilepticus has developed, treatment should be carried out in hospital, under close supervision. For the first 30-60 minutes or so of continuous seizures, physiological mechanisms compensate for the greatly enhanced metabolic activity. This is the stage of early status, and it is usual to administer a fast-acting benzodiazepine drug.

In most clinical settings, intravenous lorazepam or diazepam (but not both together) are the drugs of choice. Rectal or intramuscular paraldehyde is a useful alternative to the benzodiazepine drugs in early status, where facilities for intravenous injection or for resuscitation are not freely available (for instance in nursing homes, where it can be administered by nursing staff). In patients in respiratory failure, intravenous lignocaine may be preferable. Intravenous phenytoin is sometimes given with diazepam at this stage, although this is usually unnecessary.

In most patients, therapy will be highly effective. Twenty four hour inpatient observation should follow. In previously non-epileptic patients, chronic antiepileptic therapy should be introduced, and in those already on maintenance antiepileptic therapy, this should be reviewed.

\section{Stage of established status epilepticus (30-60/90 minutes):}

The stage of established status can be operationally defined as status which has continued for 30 minutes in spite of early-stage treatment. The time period is chosen because physiological decompensation will usually have begun. Intensive care facilities are desirable. There are three alternative first-line treatment options, all with significant drawbacks, and status at this stage carries an appreciable morbidity. These are sub-anaesthetic doses of phenobarbitone, or phenytoin, both given by intravenous loading followed by repeated oral or intravenous supplementation, or chlormethiazole given by intravenous bolus and continuous infusion. Diazepam is often given with phenytoin (either at this or the early stage of status), combining the fastacting but short-lasting effect of diazepam with the slow-onset but long-lasting effect of phenytoin.

Numerous second-line treatment options exist, including continuous intravenous infusions of clonazepam, diazepam, paraldehyde, or midazolam, at various doses. However, although once popular, continuous benzodiazepine infusions are hazardous and now not generally recommended. Lorazepam and lignocaine are essentially short term therapies, and so should not be employed at this stage.

\section{Stage of refractory status epilepticus (after 60/90 minutes):}

If seizures continue for $60-90$ minutes after the initiation of therapy, the stage of refractory status is reached and full anaesthesia required. This applies to an average case, and in many emergency situations (for example, post-operative status, severe or complicated convulsive 
status, patients already in ITU), anaesthesia can and should be introduced earlier. Prognosis will now be much poorer, and there is a high mortality and morbidity.

Anaesthesia can be induced by barbiturate or non-barbiturate drugs. A number of anaesthetics have been administered, although few have been subjected to formal evaluation and all have drawbacks. The most commonly used anaesthetics are: the intravenous barbiturate thiopentone, or the intravenous nonbarbiturate propofol. Other drugs in current use include the infusional anaesthetic isoflurane, and intravenous anaesthetics pentobarbitone (not available in the UK) and etomidate.

Patients require the full range of intensive care facilities, including EEG monitoring, and care should be shared between anaesthetist and neurologist. Experience with longterm administration (hours or days) of the newer anaesthetic drugs is very limited. The non-barbiturate anaesthetics have little intrinsic antiepileptic activity (indeed some are proconvulsant), but it is not clear to what extent (if any) this is a disadvantage. The modern anaesthetics, on the other hand, have important pharmacokinetic advantages over the more traditional barbiturates.

\section{Antiepileptic drugs}

Diazepam:

Diazepam ${ }^{19-23}$ has a time honoured place as a drug of first choice in premonitory or early stages of status. Its pharmacology and clinical effects have been extensively studied in adults, children and the newborn, and it has been shown to be highly effective in a wide range of status types. Diazepam can be given by intravenous bolus injections or by the rectal route in the premonitory stage, and has a rapid onset of action. Sufficient cerebral levels are reached within one minute of a standard intravenous injection, and rectal administration produces peak levels at about 20 minutes. The drug is rapidly redistributed, and has a relatively short duration of action after a single intravenous injection. After repeated dosing, as drug concentrations in the peripheral compartments (lipid stores) increase, this redistribution does not occur. Thus repeated bolus injections produce high peak levels which persist, carrying an attendant risk of sudden and unexpected CNS depression and cardiorespiratory collapse. Diazepam is metabolised by hepatic microsomal enzymes. Respiratory depression, hypotension and sedation are the principal side-effects. Sudden apnoea can occur, especially after repeated injections or if the injection is administered at too fast a rate.

Bolus intravenous doses of diazepam should be given in an undiluted form at a rate not exceeding $2-5 \mathrm{mg} /$ minute, using the Diazemuls formulation. Diazepam may be given rectally, either in its intravenous preparation infused from a syringe via a plastic catheter, or as the ready made proprietary rectal tube preparation Stesolid, the latter is a convenient and easy method. Diazepam sup- positories should not be used, as absorption is too slow. The adult bolus intravenous or rectal dose in status is $10-20 \mathrm{mg}$, and additional $10 \mathrm{mg}$ doses can be given at 15 minute intervals, to a maximum of $40 \mathrm{mg}$. In children, the equivalent bolus dose is $0.2-0.3 \mathrm{mg} / \mathrm{kg}$. A continuous infusion of benzodiazepine has also been used, but there is now little place for this mode of administration. The solution should be freshly prepared, and no drugs should be admixed.

The usual IV formulation is as an emulsion (Diazemuls) in a $1 \mathrm{~mL}$ ampoule containing $5 \mathrm{mg} / \mathrm{mL}$ or as a solution in $2 \mathrm{~mL}$ ampoules containing $5 \mathrm{mg} / \mathrm{mL}$. Stesolid is the usual rectal formulation, $2.5 \mathrm{~mL}$ rectal tube containing $2 \mathrm{mg} / \mathrm{mL} 4 \mathrm{mg} / \mathrm{mL}$. The IV solution can also be instilled rectally.

\section{Midazolam:}

Midazolam ${ }^{24-27}$ has only recently been recently introduced in status, and clinical experience is limited. Unique amongst the drugs in status, it can be given by intramuscular injection, as well as by the rectal or intravenous routes. Bioavailability after intramuscular injection is about $80-100 \%$, and peak levels are reached after about 25 minutes although there is marked individual variation. Its elimination kinetics are dependent on hepatic blood flow. The lipid solubility of the drug, and hence its cerebral action, is reduced as $\mathrm{pH}$ falls. Action is short-lived, and there is a strong tendency to relapse following a single bolus injection. It is cleared from the body faster than diazepam, and there is thus less tendency to accumulate. Midazolam exhibits the same toxic effects as other benzodiazepines, including sedation, hypotension and cardiorespiratory depression. Respiratory arrest may occur occasionally even after intramuscular injection so careful monitoring is imperative. Intramuscular use in premonitory status, where immediate facilities for intravenous injection are often not available, is a great advantage. This is the main current role for midazolam in status, but further experience may widen its indications.

Midazolam is usually given intramuscularly or rectally in premonitory status, at a dose of $5-10 \mathrm{mg}$ (in children $0.15-0.3 \mathrm{mg} / \mathrm{kg}$ ), which can be repeated once after 15 minutes or so. A 5-10 mg intravenous bolus injection can also be given (repeated to a maximum of $0.3 \mathrm{mg} / \mathrm{kg}$ in adults), and there is limited experience of an intravenous infusion. Midazolam is available in $5 \mathrm{~mL}$ ampoules containing $2 \mathrm{mg} / \mathrm{mL}$ or $2 \mathrm{~mL}$ ampoules containing $5 \mathrm{mg} / \mathrm{mL}$.

Paraldehyde:

Paraldehyde ${ }^{28-30}$ is a thoroughly old fashioned medication, but is still widely used in the treatment of status epilepticus. Its main indication is as an alternative or sequel to the administration of diazepam in the stage of premonitory or early status. It is especially useful in situations where intravenous administration is difficult, or where conventional antiepileptic drugs are contra-indicated or 
have proved ineffective. The drug is usually given rectally (or less often intramuscularly), and absorption by both routes is fast and complete. The onset of action is rapid and paraldehyde is effective for many hours. Seizures tend to recur less after control is achieved than with the shorter acting benzodiazepines, anaesthetic drugs or chlormethiazole. Paraldehyde has no strong tendency to accumulate, and the risks of hypotension or cardiorespiratory depression are low. Toxicity is unusual providing: the correct dose is not exceeded; the solution is freshly made; the paraldehyde is not decomposed; is diluted satisfactorily. Inappropriately diluted or decomposed paraldehyde is highly toxic by any route of administration. The intramuscular injection must be into deep (usually gluteal) muscle, well away from the sciatic nerve. In established status, paraldehyde can be given by intravenous infusion, but this is a complicated and fraught procedure, and one which is now very rarely recommended. The drug also reacts with rubber and plastic, and so if infused, must be given via glass giving sets and syringes. An injection using a plastic syringe, however, is acceptable if given rapidly after drawing the solution up.

In early status, paraldehyde can be given at a dose of $10-20 \mathrm{~mL}$ of $50 \%$ solution rectally or intramuscularly (children $0.07-0.35 \mathrm{~mL} / \mathrm{kg}$ ), which can be repeated once after 15-30 minutes.

In established status in adults, it can be given by continuous infusion, as a solution of $15 \mathrm{~mL}$ ampoules in $500 \mathrm{~mL}$ of $5 \%$ dextrose freshly made up every three hours, given at a dose of $15-30 \mathrm{~mL}$ every three hours (that is, approximately $100-200 \mathrm{mg} / \mathrm{kg} / \mathrm{h}$ ). There is now no place for the bolus injection of undiluted paraldehyde even into a fast running drip. In neonatal status, an infusion of $200 \mathrm{mg} / \mathrm{kg} / \mathrm{h}$ can be given for at least three hours, or an initial infusion of $200 \mathrm{mg} / \mathrm{kg} / \mathrm{h}$ followed by $16 \mathrm{mg} / \mathrm{kg} / \mathrm{h}$ for 12 hours.

Paraldehyde is supplied in $10 \mathrm{~mL}$ ampoules (approximately 10 grams) in darkened glass to prevent decomposition. For rectal or intramuscular administration, it is diluted in equal measure with $0.9 \%$ sodium chloride (normal saline) or arachis oil. For intravenous administration, it should be given as a $5 \%$ infusion in $5 \%$ dextrose, freshly made up every three hours.

\section{Chlormethiazole:}

Chlormethiazole ${ }^{31-34}$ is widely used at the stage of established status, by continuous intravenous infusion. Distribution is very rapid, and there is a large volume of distribution. A single intravenous injection has a very rapid effect, which is very short lived. Chlormethiazole is thus best given as a continuous infusion, and the dose can be titrated according to effect on a moment to moment basis, without inducing deep anaesthesia. This ability to titrate the dose is very useful, and unique amongst the drugs used in status. On longer-term therapy, however, as the drug concentrations in peripheral lipid com- partments approach saturation levels, this property is lost. Sudden accumulation'may cause persistingly high blood levels, resulting in sudden cardiorespiratory collapse, cardiac arrhythmia, hypotension or deep sedation. In view of this risk, prolonged use of the drug should be avoided where possible. If a longterm infusion ( $>12$ hours) is judged necessary, it is wise to reduce the dose every few hours to minimise accumulation. There is a tendency for seizures to recur as chlormethiazole is weaned, and longer-term oral supplementation is sometimes required. On prolonged therapy there is a danger of fluid overload, and electrolyte supplementation may be required as the infusion fluid is electrolyte-deficient. The elimination of chlormethiazole is markedly affected by changes in hepatic blood flow and by hepatic disease. The drug is absorbed by PVC on prolonged contact. Although its pharmacokinetics are well studied, there have been no formal clinical trials of chlormethiazole in status, and published experience of its use, especially in the long-term and in children or the newborn is very limited.

In status, an initial intravenous infusion of $40-100 \mathrm{~mL}$ of the $0.8 \%$ solution is given (that is, $320-800 \mathrm{mg}$ ) at a rate of $5-15 \mathrm{~mL} /$ minute. The infusion is continued at a minimum dose which will control seizures (commonly $0.5-4 \mathrm{~mL} /$ minute, maximum $20 \mathrm{~mL} /$ minute in adults). When seizures are controlled (for 12 hours in a case of adult status), the rate of infusion should be slowly reduced. It is not uncommon for seizures to recur on chlormethiazole withdrawal, in which case the minimum effective dose should again be determined and continued. Sometimes, switching from the intravenous to oral form (1-3 capsules of $192 \mathrm{mg}$ chlormethiazole base a day, or 1-3 $500 \mathrm{mg}$ tablets of chlormethiazole edisylate, or 5-15 mL of chlormethiazole edisylate syrup) is necessary as status resolves. An infusion rate of $0.01 \mathrm{~mL} / \mathrm{kg} /$ minute $(0.08 \mathrm{mg} / \mathrm{kg} /$ minute $)$ in children has been recommended, increasing every 2-4 hours until seizures are abolished or drowsiness intervenes. The drug is usually supplied in $500 \mathrm{~mL}$ bottles of a $0.8 \%$ solution of chlormethiazole edisylate $(8 \mathrm{mg} / \mathrm{mL})$ in dextrose and sodium hydroxide.

\section{Lorazepam:}

Lorazepam ${ }^{23}$ 35-39 is indicated in the early stage of status only, where its lack of accumulation in lipid stores, its strong cerebral binding and long duration of action are very significant advantages over diazepam. The pharmacology and clinical effects of lorazepam have been well characterised in adults, in children and in the newborn, and the drug has been the subject of large scale clinical trials. Lorazepam is remarkably effective in controlling seizures in the early stage of status. Its main disadvantage is the rapid development of tolerance. Initial injections of lorazepam are effective for about 12 hours (longer than with diazepam), but repeated doses are much 
less effective, and the drug has no place as long-term therapy. Lorazepam has sedative effects shared by all the benzodiazepine drugs used in status, but sudden hypotension or respiratory collapse are less likely because of its relative lipid-insolubility and the lack of accumulation after single bolus injections.

Lorazepam is administered by intravenous bolus injection. As distribution is slow, the rate of injection is not critical. In adults, a bolus dose of $0.07 \mathrm{mg} / \mathrm{kg}$ (to a maximum of $4 \mathrm{mg}$ ) is given, and this can be repeated once after 20 minutes if no effect has been observed. In children under 10 years, bolus doses of $0.1 \mathrm{mg} / \mathrm{kg}$ are recommended. Longterm infusion of lorazepam should not be used. It is usually available as a $1 \mathrm{~mL}$ ampoule containing $4 \mathrm{mg}$ of lorazepam.

\section{Phenytoin:}

Phenytoin ${ }^{40-43}$ is a drug of first choice in established status. Its pharmacology and clinical effects are well documented, and there is extensive experience in status in adults, children and the newborn. It is a highly effective anticonvulsant, with the particular advantage of a long duration of action. It can also be continued as chronic therapy. Phenytoin causes relatively little respiratory or cerebral depression, although hypotension is more common. The initial infusion of phenytoin takes 20-30 minutes in an adult, and the onset of action is slow. It is therefore often administered in conjunction with a short-acting drug with a rapid onset of action such as diazepam. The notorious saturable pharmacokinetics of phenytoin cause less problems in the emergency setting than in chronic therapy, but careful serum level monitoring is essential. The usual phenytoin solutions have a $\mathrm{pH}$ of 12 , and if added to bags containing large volumes of fluid at lower than physiological $\mathrm{pH}$ (for example, $5 \%$ glucose) precipitation may occur in the bag or tubing; use in a solution of $0.9 \%$ sodium chloride (normal saline) $(5-20 \mathrm{mg} / \mathrm{mL})$ is safer. There is also a serious risk of precipitation if other drugs are added to the infusion solution. Administration via a side arm, or directly using an infusion pump is preferable. Phenytoin should not be given by either rectal or intramuscular injection. ECG monitoring is advisable whilst administering phenytoin.

The rate of infusion of phenytoin solution should not exceed $50 \mathrm{mg} / \mathrm{minute}$, and it is prudent to reduce this to $20-30 \mathrm{mg} /$ minute in the elderly. The adult dose is $15-18 \mathrm{mg} / \mathrm{Kg}$; usually about $1000 \mathrm{mg}$, therefore taking at least 20 minutes to administer. Regrettably, a lower dose is too often given, which results in suboptimal cerebral levels. This is a common and potentially serious mistake. Phenytoin therapy can be continued after intravenous loading by oral or further intravenous daily dosages of $5-6 \mathrm{mg} / \mathrm{kg}$ individual doses, guided by blood level measurements. For older children, the dose of phenytoin is as for adults. For the newborn a dose of $15-20 \mathrm{mg} / \mathrm{kg}$, injected at a rate not exceeding $1 \mathrm{mg} / \mathrm{kg} / \mathrm{minute}$, should be given. Phenytoin is usually available as $5 \mathrm{~mL}$ ampoules containing phenytoin sodium $250 \mathrm{mg}$.

\section{Phenobarbitone:}

Phenobarbitone ${ }^{43-46}$ is a drug of choice for the treatment of established status. It is highly effective, has a rapid onset of action and prolonged anticonvulsant effects. It has stable and non-reactive physical properties, and convenient pharmacokinetics. Wide experience has been gained of its use in adults and in children, and few drugs are as well tried in the newborn. It has stronger anticonvulsant properties than most other barbiturates, and may be preferentially concentrated in metabolically active epileptic foci. As well as excellent anticonvulsant properties, it may also have cerebral-protective action. Acute tolerance to the antiepileptic effect is unusual, in contrast to the benzodiazepines, and once controlled, seizures do not tend to recur. The main disadvantages of phenobarbitone are its potential to cause sedation, respiratory depression and hypotension; although in practice these effects seem slight except at high levels or with rapidly rising levels, and its safety at even high doses is well established. The well-known chronic side-effects of phenobarbitone in long-term therapy are of no relevance in the emergency situation of status. The drug is eliminated slowly, and whilst this is of no importance on initial phenobarbitone loading, on prolonged therapy there is a danger of accumulation, and blood level monitoring is essential. In the newborn period dosing is more difficult than in adults, as the pharmacokinetics change rapidly during the first weeks and months of life. The drug has a strong tendency to auto-induction. Phenobarbitone is a stable preparation which does not easily decompose, nor is the drug absorbed by plastic. It should not be used in a solution containing other drugs (for example, phenytoin), as this may result in precipitation.

The usual recommended adult intravenous loading dose is $10 \mathrm{mg} / \mathrm{Kg}$, given at a rate of $100 \mathrm{mg} /$ minute (that is, a total of about $600 \mathrm{mg}$ in six minutes). This should be followed by daily maintenance doses of $1-4 \mathrm{mg} / \mathrm{kg}$. The initial maximum adult dose should not exceed $1000 \mathrm{mg}$ as the drug is not very lipid soluble and in obese patients, the $\mathrm{mg} / \mathrm{kg}$ guide may be unreliable. In neonates, initial phenobarbitone loading doses of between $12-20 \mathrm{mg} / \mathrm{kg}$ have been recommended to produce therapeutic levels, with subsequent supplementation of 3-4 mg/kg per day, to a maximum dose of $40 \mathrm{mg} / \mathrm{kg}$. In older children, loading dose of between $5-20 \mathrm{mg} / \mathrm{kg}$ are recommended and maintenance doses of $1-4 \mathrm{mg} / \mathrm{kg}$, although much higher doses have been safely given. After loading, maintenance doses can be given by the oral, intravenous or intramuscular route. Phenobarbitone is usually presented in $1 \mathrm{~mL}$ ampoules containing $200 \mathrm{mg}$ of phenobarbitone sodium.

\section{Thiopentone:}

Thiopentone $\mathrm{e}^{47-50}$ is the compound traditionally used for barbiturate anaesthesia in status 
epilepticus, at least in Europe. It is an effective antiepileptic drug, and may have additional cerebral-protective effects. In the doses used in status it has anaesthetic action, and all patients require intubation and most artificial ventilation. The most troublesome sideeffect is persisting hypotension and many patients require pressor therapy. Thiopentone has saturable pharmacokinetics, and a strong tendency to accumulate. Thus if large doses are given, blood levels may remain very high for protracted periods, and days may pass before consciousness is recovered after drug administration is discontinued. Blood level monitoring, both of the thiopentone and its active metabolite pentobarbitone, is therefore essential on prolonged therapy. Other toxic effects on prolonged therapy include pancreatitis and hepatic disturbance, and thiopentone may cause acute hypersensitivity. It should be administered cautiously in the elderly, and in those with cardiac, hepatic or renal disease. Although it has been in use since the 1960 s in status, formal clinical trials of its safety and effectiveness in either adults and children are few. A full range of ITU facilities are required during thiopentone infusions. Central venous pressure should be monitored, and blood pressure via an arterial line. Swan-Ganz monitoring is sometimes advisable, and EEG or cerebral function monitoring is essential if thiopentone infusions are prolonged. A concomitant dopamine infusion is frequently needed to maintain blood pressure. Thiopentone can react with polyvinyl infusion bags or giving sets. The continuous infusion should be made up in $0.9 \%$ sodium chloride (normal saline). The intravenous solution has a $\mathrm{pH}$ of $10 \cdot 2-11 \cdot 2$, is incompatible with a large number of acidic or oxidising substances, and no drugs should be added. The aqueous solution is unstable if exposed to air.

The dose regime commonly used is as follows: thiopentone is given as a $100-250 \mathrm{mg}$ bolus over 20 seconds, with further $50 \mathrm{mg}$ boluses every 2-3 minutes until seizures are controlled, with intubation and artificial ventilation. The intravenous infusion is then continued at the minimum dose required to control seizure activity (burst suppression on the EEG), usually between 3-5 mg/kg/hour, and at thiopentone blood levels of about $40 \mathrm{mg} / \mathrm{L}$. After 24 hours, the dose should be controlled by blood level monitoring. After 2-3 days or so, metabolism may be near saturation, and daily or twice daily blood level estimations should be made to ensure that levels do not rise excessively. The dose should be lowered if systolic blood pressure falls below $90 \mathrm{~mm} \mathrm{Hg}$, or if vital functions are impaired. Thiopentone should be continued for no less than 12 hours after seizure activity has ceased, and then slowly discontinued. The usual preparation is as a $2.5 \mathrm{~g}$ vial with $100 \mathrm{~mL}$ of diluent to produce a $2 \cdot 5 \%$ solution.

Propofol:

In recent times, there has been a vogue for the use of non-barbiturate anaesthesia in status; of the currently available compounds, propofol $^{51-54}$ is probably the drug of choice. Published experience, however, is very limited of its use in status, or indeed of its longterm administration in any clinical situation. Propofol is a highly effective and nontoxic anaesthetic. Although, in experimental models, it has intrinsic anticonvulsant properties, it has caused seizures in anaesthetic practice. Propofol is extremely soluble in lipid, and has a high volume of distribution. It thus acts extremely rapidly in status. Its effects are maintained whilst the infusion is continued, and recovery following discontinuation of the drug is also very quick; in marked contrast to thiopentone. Theoretically, there is a danger of accumulation on very long-term therapy, but this has been reported in practice. Propofol administration causes profound respiratory and cerebral depression, requiring the use of assisted respiration, the full panoply of intensive care and monitoring, but only mild hypotension, and has few cardiovascular side effects. Long term administration causes marked lipaemia and may result in acidosis. It may cause involuntary movements which should not be mistaken for seizures. Although propofol has been the subject of only a few case reports, it is widely used in status, and warrants further formal study. Its safety in young children has not been established.

In status, the following regime can be used: initially a $2 \mathrm{mg} / \mathrm{kg}$ bolus dose is given, which can be repeated if seizures continue, succeeded by an infusion of $5-10 \mathrm{mg} / \mathrm{kg} /$ hour guided by EEG. The dose should be gradually reduced, and the infusion tapered 12 hours after seizure activity is halted. In the elderly, doses should be lower. It is available as $20 \mathrm{~mL}$ ampoules containing $10 \mathrm{mg} / \mathrm{mL}$, as an emulsion.

Other drugs:

A wide variety of other drugs have been used in status, including clonazepam, lignocaine, pentobarbitone, etomidate, magnesium sulphate, clorazepate, corticosteroids, valproate, lamotrigine. Few of these (or indeed the firstline) drugs have received adequate formal clinical study in status, and their relative merits are largely uncertain. An exciting area of future research is the use of cerebro-protective agents, to prevent status-induced cerebral damage. A more detailed discussion of the

Table 6 Common reasons for the failure of emergency drug therapy to control seizures in status epilepticus

Inadequate emergency antiepileptic drug therapy (especially the administration of drugs at too low a dose)

Failure to initiate maintenance antiepileptic drug therapy (seizures will recur as the effect of emergency drug treatment wears off)

Hypoxia, hypotension, cardiorespiratory failure, metabolic disturbance

Failure to identify the underlying cause

Failure to identify other medical complications (includin hyperthermia, disseminated intravascular coagulation, hepatic failure)

Misdiagnosis (pseudostatus is more common than epileptic status at least in specialist neurological practice) 
drugs used in status can be found in larger reviews. ${ }^{21655}$

\section{Failure of antiepileptic treatment}

The antiepileptic drugs used in status are highly effective. If seizures continue despite emergency therapy, it is important to reassess the clinical circumstances, as there are often complicating remediable factors influencing the response to treatment. The most common of these are listed in table 6.

1 Hauser WA. Status epilepticus: epidemiological considerations Neurology 1990;40(suppl 2):9-12.

2 Shorvon SD. Status epilepticus: its clinical features and treatment in children and adults. Cambridge: Cambridge University Press, 1993.

3 Aicardi J, Chevrie JJ. Convulsive status epilepticus in infants and children. A study of 239 cases. Epilepsia

4 Goulon M, Levy-Alcover MA, Nouailhat F. Etat de mal epileptique de l'adulte. Etude epidemiologique et clinique en reanimation. Rev EEG Neurophysiol 1985; 14:277-85

5 Pilke A, Partinen M, Kovanen J. Status epilepticus and alcohol abuse: an analysis of 82 status epilepticus admissions. Acta Neurol Scand 1984;70:443-50.

6 Aicardi J, Chevrie JJ. Consequences of status epilepticus in infants and children. In: Delgado-Escueta AV, Wasterlain CG, Treiman DM, Porter RJ, eds. Status epilepticus: mechanisms of brain damage and treatment. Advances in Neurology, Vol 34. New York: Raven Press, 1983:115-125.

7 Bourneville DM. Recherches cliniques et therapeutiques sur l'epilepsie et l'hysterie. Progres Medical. Paris:

8 Roger J, Lob H, Tassinari C. Status epilepticus. In: Vinken PJ, Bruyn GW, eds. Handbook of clinical neurology, Vol 15. New York: Elsevier, 1974:145-188.

9 Treiman DM, Walton NY, Kendrick C. A progressive sequence of electroencephalographic changes during generalised convulsive status epilepticus Epilepsy Research 1990;5:49-60.

10 Lothman E. The biochemical basis and pathophysiology of status epilepticus. Neurology 1990;40(suppl 2):13-22.

11 Simon RP. Physiological consequences of status epilepticus. Epilepsia 1985;26(Suppl 1):S58-66.

12 Brown JK, Hussain IHMI. Status epilepticus: 1: Pathogenesis. Develop Med Child Neurol 1991;33:3-17

13 Aminoff MJ, Simon RP. Status epilepticus: causes, clinical features and consequences in 98 patients. $\mathrm{Am} \mathcal{f}$ of

14 Meldrum BS. Metabolic factors during prolonged seizures and their relation to cell death. In: Delgado Escueta AV, Wasterlain CG, Treiman DM, Porter RJ, eds. Status epilepticus: mechanisms of brain damage and treatment. Advances in neurology, vol 34. New York: Raven Press, 1983:261-75.

15 Delgado-Escueta AV, Ward AA, Woodbury DM, Porter RJ, eds. Basic mechanisms of the epilepsies; molecular and cellular approaches. Advances in neurology, vol 44. New Yollular approaches. Advan Press, 1986

16 Delgado-Escueta AV, Wasterlain CG, Treiman DM, Porter RJ, eds. Status epilepticus: mechanisms of brain Porter RJ, eds. Status epilepticus: mechanisms of brain New York: Raven Press, 1983.

17 Benowitz NL, Simon RP, Copeland JR. Status epilepticus: divergence of sympathetic activity and cardiovascular response. Ann Neurol 1986;19:197-199.

18 Young RSK, Fripp RR, Yagel SK, Werner JC, McGrath G, Schuler HG. Cardiac dysfunction during status epilepticus in the neonatal pig. Ann Neurol 1985;18:291-7.

19 Schmidt D. Diazepam. In: Levy R, Dreifuss FE, Mattson R, Meldrum B, Penry JK, eds. Antiepileptic drugs, 3rd ed. New York: Raven Press, 1989:735-64.

20 Schmidt D. Benzodiazepines- an update In: Pedley TA and Meldrum BS, eds. Recent advances in epilepsy, vol 2. Edinburgh: Churchill Livingstone, 1985:125-135.

21 Delgado-Escueta AV, Enrile-Bacsal F. Combination therapy for status epilepticus: intravenous diazepam and phenytoin. In: Delgado Escueta AV, Wasterlain CG, phenytoin. In: Delgado Escueta AV, Wasterlain CG, nisms of brain damage and treatment. Advances in neurolonisms of brain damage and treatment. Advances in

22 Remy C, Jourdil N, Villemain D, Favel P, Genton P. Intrarectal diazepam in epileptic adults. Epilepsia 1992;33:353-8.

23 Leppik IE, Derivan AT, Homan RW, Walker J, Ramsay RE, Patrick B. Double-blind study of lorazepam and diazepam in status epilepticus. $\mathcal{F} \mathrm{Am}$ Med Assoc 1983;249:1452-4

24 Dundee JW, Halliday NJ, Harper KW, Brogden RN.
Midazolam: a review of its pharmacological properties and therapeutic uses. Drugs 1984;28:519-43.

25 Galvin GM, Jelinek GA. Midazolam: an effective intravenous agent for seizure control. Archives of Emergency Medicine 1987;4:169-172.

26 Ghilain S, Van Rijckevorsel-Harmant K, de Barsy TH. Midazolam in the treatment of epileptic seizures. $\mathcal{F}$ of Neurol, Neurosurg Psychiatry 1988;51:732.

27 Jawad S, Oxley J, Wilson J, Richens A. A pharmacodynamic evaluation of midazolam as an antiepileptic com namic evaluation of midazolam as an antiepileptic com-

28 Koren G, Butt W, Rajchgot P, Mayer J, Whyte H, Pape $\mathrm{K}$, MacLeod SM. Intravenous paraldehyde for seizure control in newborn infants. Neurology 1986;36:108-111.

29 Browne TR. Paraldehyde, Chlormethiazole, and Lidocaine for treatment of status epilepticus. In: Delgado Escueta AV, Wasterlain CG, Treiman DM, Porter RJ, eds. Status epilepticus: mechanisms of brain damage and treatment. Advances in neurology, vol 34. New York: Raven Press, 1983:509-17.

30 Lockman LA. Paraldehyde. In: Levy RH, Dreifuss FE, Mattson RH, Meldrum BS, Penry JK, eds. Antiepileptic Drugs, 3rd ed. New York: Raven Press, 1989:881-6.

31 Harvey PKP, Higenbottam TW, Loh L. Chlormethiazole in treatment of status epilepticus $B M \mathcal{F} 1975 ; 2: 603-5$.

32 Miller P, Kovar I. Chlormethiazole in the treatment of neonatal status epilepticus. Postgrad Med $\mathcal{F}$ 1983;59: 801-2.

33 Lingam S, Bertwistle H, Elliston $\mathrm{H}$, Wilson J. Problems with intravenous chlormethiazole (Heminevrin) in status epilepticus $B M \mathcal{F} 1980 ; \mathbf{i}: 155-6$.

34 Laxenaire $M$, Tridon $P$, Poire P. Effect of chlormethiazole in treatment of delirium tremens and status epilepticus. Acta Psychiatrica Scand 1966;42(Suppl 192):87-102.

35 Crawford TO, Mitchell WG, Snodgrass SR. Lorazepam in childhood status epilepticus and serial seizures: effectiveness and tachyphylaxis. Neurology 1987;37:190-5.

36 Sorel L, Mechler L, Harmant J. Comparative trial of intravenous lorazepam and clonazepam in status epilepticus. Clinical Therapeutics 1981;4:326-36.

37 Homan RW, Unwin DH Benzodiazepines: lorazepam. In: Levy R, Dreifuss FE, Mattson R, Meldrum B, Penry JK, eds. Antiepileptic drugs, 3rd ed. New York: Raven Press, 1989:841-54

38 Mitchell WG, Crawford TO. Lorazepam is the treatment of choice for status epilepticus. $\mathcal{F}$ Epilepsy 1990;3:7-10.

39 Maytal J, Novak GP, King KC. Lorazepam in the treatment of refractory neonatal seizures. $\mathcal{F}$ Child Neurol 1991;6:319-23.

40 Wallis W, Kutt H, McDowell F. IV diphenylhydantoin in treatment of acute repetitive seizures. Neurology 1968; 18:513-25.

41 Leppik IE, Patrick BK, Cranford RE. Treatment of Acute Seizures and Status Epilepticus with Intravenous Phenytoin. In: Delgado-Escueta AV, Wasterlain CG, Treiman DM, Porter RJ, eds. Status epilepticus: mechanisms of brain damage and treatment. Advances in neurolonisms of brain damage and treatment. Advances in neurc

42 Cranford RE, Leppik IE, Patrick B, Anderson CB Kostick B. Intravenous phenytoin: clinical and pharmaKostick B. Intravenous phenytoin: clinical and
cokinetic aspects. Neurology 1978;28:874-80.

43 Shaner DM, McCurdy SA, Herring MO, Gabor AJ. Treatment of status epilepticus: a prospective comparison of diazepam and phenytoin versus phenobarbital and optional phenytoin. Neurology 1988;38:202-7.

44 Crawford TO, Mitchell WG, Fishman LS, Snodgrass R. Very-high-dose phenobarbital for refractory status epilepticus in children. Neurology 1988;38:1035-40.

45 Gal P, Toback J, Boer HR, Erkan NV, Wells TJ. Efficacy of phenobarbital monotherapy in treatment of neonatal seizures-relationship to blood levels. Neurology 1982;32:1401-4.

46 Lockman LA, Kriel R, Zaske D, Thompson T, Virnig N. Phenobarbital dosage for control of neonatal seizures. Neurology 1979;29:1445-9.

47 Partinen M, Kovanen J, Nilsson E. Status epilepticus treated with barbiturate anaesthesia with continuous monitoring of cerebral function. $B M F$ 1981;282:520-21.

48 Young EB, Blume WT, Bolton CF, Warren KG. Anesthetic barbiturates in refractory status epilepticus fournal Canadien des Sciences Neurologiques 1980;7: 291-2.

49 Orlowski JP, Erenberg G, Lueders H, Cruse RP. Hypothermia and barbiturate coma for refractory status epilepticus. Critical Care Medicine 1984;12:367-72.

50 Lowenstein DH, Aminoff MJ, Simon RJ. Barbiturate anesthesia in the treatment of status epilepticus: clinical experience of 14 patients. Neurology 1988;38:395-400.

51 MacKenzie SJ, Kapadia F, Grant IS. Propofol infusion for control of status epilepticus. Anaesthesia 1990;45: 1043-5.

52 De Maria G, Guarneri D, Pasolini MP, Antonini L. Stato di male versivo trattato con Propofol. Boll Lega It Epil 1991;74:191-192.

53 Alia G, Natale E, Mattaliano A, Daniele O. On two cases of status epilepticus treated with propofol. Epilepsia 1991;32(suppl 1):77.

54 Wood PR, Browne GPR, Pugh S. Propofol infusion for the treatment of status epilepticus. Lancet 1988;i:480-1.

55 Levy R, Dreifuss FE, Mattson R, Meldrum B, Penry JK eds. Antiepileptic drugs, 3rd ed. New York: Raven Press, 1989. 